\title{
EDITORIAL
}

\section{Microbial genomics: an increasingly revealing interface in human health and disease}

\author{
Martin L Hibberd*
}

The diverse microbial communities associated with humans are now beginning to be comprehensively interrogated and characterized, thanks to new genomic, metagenomic and other high-throughput approaches. However, there is a huge amount of work to be done that will require a large-scale effort from the scientific community, particularly in the development and application of analysis tools and in achieving a biological understanding of the human-microbe interface. This endeavor has already begun with projects such as MetaHIT [1] and the Human Microbiome Project Consortium [2] taking advantage of the extensive advances made with the advent of highly parallel next-generation sequencing approaches. But I would call for one additional effort: in the midst of all the thousands of microbial genomes, the role of one additional genome the human genome - should also be fully evaluated. It is becoming increasingly clear that human genetic variants, particularly in microbial sensing genes, might influence the structure of the human-associated microbial communities and lead to diseases such as inflammatory bowel disease [3]. Interestingly, the shaping of these microbial communities, influenced by the human genome, might occur during the early colonization following birth and might influence many of the subsequent microbiome interactions.

Genome-scale methods allow us to move away from targeted investigations, which are necessarily limited to our knowledge of candidate genes, to population-based analyses that permit the full genomic repertoire to be interrogated, enabling the discovery of key mutations and mechanisms that drive host-microbe (and microbemicrobe) interactions in their natural environment. However, even when all the genes in a genome have been identified, detailed studies at the molecular level are required to provide novel mechanistic insights. Without such understanding, the statistical associations between

\footnotetext{
*Correspondence: martin.hibberd@lshtm.ac.uk

London School of Hygiene \& Tropical Medicine, Keppel Street, London WC1E 7HT, UK
}

microbial genes and their products that are currently being linked to medical outcomes may not stand firm.

In this issue, we launch a new article series highlighting the application of genomic and other high-throughput approaches to investigate the role of microbes in human health and disease. Forthcoming articles will feature recent progress in characterizing, detecting, monitoring and understanding the underlying mechanisms involved in infectious diseases, the role of the microbiome, and how such information can be applied to medicine. There is great potential in this field, from basic and technological advances to their application and integration into clinical approaches for disease prediction, surveillance, diagnosis and treatment.

\section{Microbes in health}

The study of microbes associated with humans has been dominated by investigations of pathogens. In the past, microbes not implicated in disease causation have been thought of as hardly interacting with their host at all, or as friendly commensals providing benefits without consequences. This has led to the idea of pathogen-associated molecular pattern molecules [4] and microbial compartmentalization [5], which is postulated to explain how these microbes could interact with the immune system and yet not cause disease.

A wealth of literature now shows that host-microbial interactions can be much more complex and dynamic than previously understood, with a constant flow of information that can have far reaching consequences [6]. For example, in one study looking at the global host response to commensal bacteria using a bronchial epithelial cell line, commensals were shown to invade the cells, ellicit an inflammatory response, and then proceed to cause an increase in host metabolism [7], which corresponded with a reduction in bacterial metabolism [8]. These harmless commensals were consuming host nutrients and initiating a complex interaction process. This type of interaction may be common and might provide clues to explain how commensals interacting with a healthy host could have consequences that reach beyond their local environment - for example, to the liver [9] or the brain [10]. In turn, a wider understanding of 
the consequences of microbe-host interactions could give new insight into their roles in health [11], and begin to provide mechanistic explanations of the statistical associations between microbes and medical outcomes. This will be complex work because there is the diversity of microbial niches to consider along with microbial diversity [12], and we have, so far, little idea of the relative importance of each. However, genome-wide approaches to investigate gene expression at the transcriptional, proteomic or other 'omic levels will reveal insights into the pathways and mechanisms involved; even while generating a systems-biology-scale problem of integration in the process. Analysis of the bacterial transcriptome in particular seems likely to identify the active genes, metabolism and pathways within each microbial niche, and when linked to other genomic data might lead the way in determining the mechanisms of interaction with the host.

\section{Microbes in disease}

There is a well-established role for specific pathogens in human disease; and we are now starting to describe this in detail through the understanding generated by genomic tools [13]. Recent studies, such as those highlighting the spread of cholera [14] and influenza [15], have used whole-genome sequencing to set new standards in explaining the spread of disease. Furthermore, genomics is revealing that the growth of pathogens may be enhanced by imbalances in commensal microbial communities (such as those caused by antibiotics), leading to the exploration of approaches aimed at correcting these imbalances [16]. This is an example of how genomics can be used to discover new knowledge, suggest therapies and then monitor their consequences.

However, the field of microbial metagenomics is perhaps at its most informative when proposing novel ways of how microbes can cause disease. There is growing evidence, based on our burgeoning understanding of how microbes interact with their host, that diseases once thought not to be microbe-related may in fact have microbial components. Statistical associations between gut microbes and metabolic diseases such as diabetes have led to the concept that microbial metabolism may affect host metabolism [17]. The interactions may in fact be even more complex, as shown in a recent study of autoimmune diabetes [18] in which a distinct blurring between pathogen and commensal, health and long-term disease was demonstrated. Only large scale 'omics studies can provide the data for hypothesis-generation that will hopefully provide novel therapy options.

Taken together, advances in understanding the role of microbes in health and disease are expected to revolutionize the field of clinical microbiology, facilitating the development of novel drugs and other interventions to control infection and disease, both for personalized medicine and for public health. However, further progress will rely on the involvement and collaboration of basic and clinical research communities from diverse disciplines and geographic regions to address the many challenges that lie ahead, including the development and application of high-throughput and bioinformatic approaches as well as methodologies for data sharing and analysis.

\section{Competing interests}

The author declares that he has no competing interests.

\section{Acknowledgements}

The author is supported by the London School of Hygiene and Tropical Medicine and the Genome Institute of Singapore, with adjunct positions at the National University of Singapore's School of Public Health and at the Wellcome Trust's Sanger Institute.

Published: 18 April 2013

\section{References}

1. Qin J, Li R, Raes J, Arumugam M, Burgdorf KS, Manichanh C, Nielsen T, Pons N, Levenez F, Yamada T, Mende DR, Li J, Xu J, Li S, Li D, Cao J, Wang B, Liang H, Zheng H, Xie Y, Tap J, Lepage P, Bertalan M, Batto JM, Hansen T, Le Paslier D, Linneberg A, Nielsen HB, Pelletier E, Renault $P$, et al:: A human gut microbial gene catalogue established by metagenomic sequencing. Nature 2010 464:59-65.

2. Human Microbiome Project Consortium: A framework for human microbiome research. Nature 2012, 486:215-21.

3. McGovern DP, Gardet A, Törkvist L, Goyette P, Essers J, Taylor KD, Neale BM, Ong RT, Lagacé C, Li C, Green T, Stevens CR, Beauchamp C, Fleshner PR, Carlson M, D'Amato M, Halfvarson J, Hibberd ML, Lördal M, Padyukov L, Andriulli A, Colombo E, Latiano A, Palmieri O, Bernard EJ, Deslandres C, Hommes DW, de Jong DJ, Stokkers PC, Weersma RK; The NIDDK IBD Genetics Consortium, Sharma Y, Silverberg MS, Cho JH, Wu J, Roeder K, Brant SR, Schumm LP, Duerr RH, Dubinsky MC, Glazer NL, Haritunians T, Ippoliti A, Melmed GY, Siscovick DS, Vasiliauskas EA, Targan SR, Annese V, Wijmenga C, Pettersson S, Rotter JI, Xavier RJ, Daly MJ, Rioux JD, Seielstad M: Genomewide association identifies multiple ulcerative colitis susceptibility loci. Nat Genet 2010, 42:332-7.

4. Tang D, Kang R, Coyne CB, Zeh HJ, Lotze MT: PAMPs and DAMPs: signals that spur autophagy and immunity. Immunol Rev 2012, 249:158-75.

5. Hooper LV, Littman DR, Macpherson AJ: Interactions between the microbiota and the immune system. Science 2012, 336:1268-1273.

6. Ivanov II, Honda K: Intestinal commensal microbes as immune modulators. Cell Host Microbe 2012, 12:496-508.

7. Wong HE, Li MS, Kroll JS, Hibberd ML, Langford PR: Genome wide expression profiling reveals suppression of host defence responses during colonisation by Neisseria meningitidis but not N. lactamica. PLOS One 2011, 6:e26130.

8. Grifantini R, Bartolini E, Muzzi A, Draghi M, Frigimelica E, Berger J, Randazzo F, Grandi G: Gene expression profile in Neisseria meningitidis and Neisseria lactamica upon host-cell contact: from basic research to vaccine development. Ann N Y Acad Sci 2002, 975:202-216.

9. Björkholm B, Bok CM, Lundin A, Rafter J, Hibberd ML, Pettersson S: Intestinal microbiota regulate xenobiotic metabolism in the liver. PLoS One 2009, 4:e6958.

10. Diaz Heijtz R, Wang S, Anuar F, Qian Y, Björkholm B, Samuelsson A, Hibberd $M L$, Forssberg H, Pettersson S: Normal gut microbiota modulates brain development and behavior. Proc Natl Acad Sci U S A 2011, 108:3047-3052.

11. Tchaptchet $S$, Hansen J: The Yin and Yang of host-commensal mutualism. Gut Microbes 2011, 2:347-352.

12. Human Microbiome Project Consortium: Structure, function and diversity of the healthy human microbiome. Nature 2012, 486:207-214.

13. Relman DA: Microbial genomics and infectious diseases. N Engl J Med 2011, 365:347-357.

14. Mutreja A, Kim DW, Thomson NR, Connor TR, Lee JH, Kariuki S, Croucher NJ, Choi SY, Harris SR, Lebens M, Niyogi SK, Kim EJ, Ramamurthy T, Chun J, Wood 
JL, Clemens JD, Czerkinsky C, Nair GB, Holmgren J, Parkhill J, Dougan G: Evidence for several waves of global transmission in the seventh cholera pandemic. Nature 2011, 477:462-465.

15. Lee VJ, Yap J, Cook AR, Chen MI, Tay JK, Tan BH, Loh JP, Chew SW, Koh WH, Lin R, Cui L, Lee CW, Sung WK, Wong CW, Hibberd ML, Kang WL, Seet B, Tambyah PA: Oseltamivir ring prophylaxis for containment of 2009 H1N1 influenza outbreaks. N Engl J Med 2010, 362:2166-2174.

16. van Nood E, Vrieze A, Nieuwdorp M, Fuentes S, Zoetendal EG, de Vos WM, Visser CE, Kuijper EJ, Bartelsman JF, Tijssen JG, Speelman P, Dijkgraaf MG Keller JJ: Duodenal infusion of donor feces for recurrent Clostridium difficile. N Engl I Med 2013, 368:407-415.

17. Tremaroli V, Bäckhed F: Functional interactions between the gut microbiota and host metabolism. Nature 2012, 489:242-249.
18. Markle JG, Frank DN, Mortin-Toth S, Robertson CE, Feazel LM, Rolle-Kampczyk $U$, von Bergen M, McCoy KD, Macpherson AJ, Danska JS: Sex differences in the gut microbiome drive hormone-dependent regulation of autoimmunity. Science 2013, 339:1084-1088.

doi:10.1186/gm435

Cite this article as: Hibberd ML: Microbial genomics: an increasingly revealing interface in human health and disease. Genome Medicine 2013, $5: 31$. 